\title{
Depression and family functioning fu in elderly
}

\author{
Summary \\ Introduction: The family is the fundamental group to increase the health status of \\ the elderly as it promotes well-being and psycho-emotional development in which \\ depression is considered a public health problem that involves not only family \\ intervention but also that of the Health sector.
}

Objective: To determine the relationship between depression and family functioning in the elderly who goes to a second-level health care unit in Cd Victoria Tamaulipas, Mexico.

Methodology: Quantitative, descriptive-cross-sectional and correlational study with 139 elderly adults in a local health institution using simple random probabilistic sampling, through interview and application of the family Apgar and Yesavage scale.

Results: Average age 68.14 years, female predominance $63 \%$, with primary schooling $87 \%$. with absence of depressive symptomatology $80 \%, 81 \%$ under a norm functional family environment.

Conclusion: If there is a relationship between both variables.

Keywords: family functionality, depression, elderly, behavior, psycho-emotional, depressive symptoms, family environment, relationship, family member, dysfunctional family outcome, disease, primary network
Volume 2 Issue 4 - 2018

\author{
Rodríguez-Tovar Guadalupe Liliana,' \\ Medrano-Martínez Ma Ramona, ${ }^{2}$ Castro- \\ García Rosa Idalia, ${ }^{3}$ Rivera - Vázquez \\ Patricia ${ }^{1,4}$ \\ 'Degree in Nursing, General Hospital of Cd.Victoria, Mexico \\ 2 Master of Health Sciences, Full-time Professor Faculty of \\ Nursing Universidad Autónoma de Tamaulipas Campus Victoria, \\ Mexico \\ ${ }^{3}$ Master of Nursing Science, Full-time Professor of Nursing \\ School of the Autonomous University of Tamaulipas Campus \\ Victoria, Mexico \\ ${ }^{4}$ Master of Health Sciences, Nurse Specialist Hospital General \\ of CdVictoria, Faculty of Nursing Universidad Autónoma de \\ Tamaulipas Campus Victoria, Mexico
}

\begin{abstract}
Correspondence: Rivera - Vázquez Patricia, Master of Health Sciences. Nurse Specialist Hospital General of CdVictoria, Dr. Norberto Treviño Zapata, Coordinator of Research in Nursing Regional Hospital of High Specialty Cd.Victoria, Professor Faculty of Nursing Universidad Autónoma de Tamaulipas Campus Victoria, Mexico, Email pattyri@live.com.mx
\end{abstract}

Received: August 13,2018 | Published: August 31, 2018

\section{Introduction}

Increase in the adult population mayore is synonymous with vulnerability, our country was detected in 7.4 million Mexican households at least one family member is over 60 years, this giving a total of 26.9 million seniors Developing within a family environment. ${ }^{1}$ Therefore, the family is the fundamental group to increase the state of health of the populations, in this case of the older adult. So familiar functionality must be addressed considering its different dimensions as Intera dynamic cionalc, effective behavior, ability to cope with the changes and development of its members according to the requirements of each stage of life, from infant age until the stage of old age. ${ }^{2}$ Considering that adequate family functionality promotes well-being, psycho-emotional development is observed when the signs of affection and family communication are replaced by negative behaviors where members prefer to spend time in front of technological devices. These behaviors lead to severe crises leading to its components to a dysfunctional family outcome. ${ }^{3,4}$ Which in turn favors and the process of aging physical and mental impairment in humans, at this stage the family is considered as the main source of direct support conoc also going as primary network since $\mathrm{s}$ is generated and has seen that older adults who do not have this family support have higher rates of mortality, cognitive alterations and depression. Although, this stage is not a disease, if it implies a decrease in autonomy and functional capacity ${ }^{5}$ The prevalence of depression ranges from $1 \%$ to $3 \%$, while its symptomatology is much higher when presented from $10 \%$ to $50 \%$. Due to the magnitude of this disorder, depression is considered a public health problem that involves not only family intervention but also that of the health sector. ${ }^{6,7}$ This being important for nursing that establishes its diagnoses and interventions based on these responses human beings considering that depressive problems cause 800 thousand suicides each year, where in many of the cases the detection and treatment did not take place in a timely manner. ${ }^{8}$
In our country, it has been shown that depression is present in $11.6 \%$ of older adults where the home environment plays an important role in the development of depressive disorders, especially in women despite receiving social support from their family, There are cases where family situations that generate stress are perceived, where the children are the main generator, so it is important to also inquire about the status. Familiar and addressed from this aspect ${ }^{9-13}$ In this regard, studies have been found that show that patients with depression are from dysfunctional families, of which only a minority are in mild to moderate depression, pointing out that Those subjects belonging to dysfunctional families are chaotic corresponding more prone to depressive disorders and established two ${ }^{14-16}$ whereas older adults who are immersed in a cohesive family environment reduce their depressive symptomatology. ${ }^{17}$ For this reason, this research aims to describe the relationship between family functionality and depression in older adults who attend a health institution and is based on the Hildegard Peplau psychodynamic nursing theory which highlights the dynamics of interaction between nurse and individual (in this case older adult) to achieve the highest degree of personal development for him. ${ }^{18-20}$

\section{Objective}

Determine the relationship between depression and family functioning in the elderly who comes to a health unit secondary care in Ciudad Victoria Tamaulipas, Mexico.

\section{Material and methods}

Study of quantitative, descriptive-transversal and correlational type carried out with a population of older adults considering as inclusion criteria patients with outpatient treatment, patients without cognitive and/or physical alterations who come to the Hospital with a willingness to participate, corroborating it with their 
signature and name in the informed consent. We worked with 139 patients alculation result of finite taking error as a percentage of $6 \%, 85 \%$ reliability during the 1 st February to July 31 , 2016. Using simple random probabilistic sampling. For the data collection, the interview technique was applied with an average duration of 20 minutes, using 2 instruments: the Family Apgar, which assesses the state of the family function, with 5 questions with scores of 0 to 2 in each item. In its sum of 0 to 3 points it shows evidence of a severely dysfunctional family, 4 to 7 moderately dysfunctional and 8 to 10 norm functional. Designed by Smilkstein ${ }^{21}$ in 1978. To evaluate the state of dermisión the Yesavage scale was used in its version of 15 items with a dichotomous response and a value of 1 or 0 points. The questions: $2,3,4,6,8,9,10,12,14$ and 15 are negative, that is; when answered affirmatively, the value of 1 is assigned and there is an inclination for depressive symptomatology. In questions 1 , $5,7,11$ and 13 when answering affirmatively, a value of 0 is assigned and there is a tendency to a more positive and satisfactory attitude. It ends with the sum of points establishing that from 0 to 4 points the person obtains a normal diagnosis and greater than 5 points begins a depressive symptomatology.22

\section{Statistic analysis}

The analysis of the data was done through the Computational Program Statics Program for Social Science (SPSS) V.22 using descriptive and inferential statistics using measures of central tendency (mean) to analyze the sociodemographic data, types of family functionality and level of depression. To establish a relationship between family functionality and depression, a descriptive statistic was used using Pearson's Chi square.

\section{Results}

At the end of the investigation it was found that the elderly patients were characterized by being in the range of 60 to 71 years, average of 68.14 years, a median of 67 , fashion of 60 years, SD 6.15, mostly of the female gender in a $63 \%(88)$, with primary schooling in $87 \%$ (121), married $70 \%$ (97) of the participants (Table 1).

Table I Sociodemographic data of older adults studied

\begin{tabular}{lll}
\hline Variables & No. Cases & \\
\hline Age & $60-67$ years & 71 \\
& $68-75$ years & 51 \\
& $76-83$ years & 13 \\
& More than 84 years & 4 \\
Gender & Female & 87 \\
Scholarship & Male & 52 \\
& Priterate & 11 \\
& Secondary & 87 \\
& Preparatory /technical & 18 \\
& Bachelor & 12 \\
& No partner & 29 \\
& with parter & 110
\end{tabular}

Source: Personal data card $\mathrm{n}=139$
The Yesavage scale showed 111 cases $(80 \%)$ with absence of depressive symptoms, 20 cases (14\%) with mild depression, and 8 cases $(6 \%)$ with established depression $12 \%$ of the subjects were not satisfied with their life. 68 subjects (49\%) report continuing to perform the same activities as usual, although they are the main cause of the lack of energy. Regarding the statement that his life is empty 32 people (23\%) reported feelings of emptiness in his life. Regarding their state of mind, which is often handled by 108 subjects (78\%), they reported a good steady state of mind while 31 subjects $(22 \%)$ reported managing a negative state of mind.A question of insecurity when they are away from home. When asked about feeling happy, 122 cases $(88 \%)$ reported a state of happiness and constant optimism, while in 17 cases $(12 \%)$ a greater state of pessimism and reluctance was reported. On the issue of abandonment 116 people (83\%) refier to feel included $\mathrm{s}$ and take $\mathrm{s}$ into account by other people while in 23 cases (17\%) reported feelings of detachment and lack of attention from society and family. About their reference for staying at home instead of leaving $86(62 \%)$ cases mention being attracted to the idea of leaving home in case of having the time and means to do so, while in $53(38 \%)$ cases showed disinterest with the idea of leaving home preferring to stay in it as long as possible.

When asked about memory problems $116(83 \%)$ people reported not feeling more trouble than the rest of the people, referring only to forgetting things occasionally or very infrequently. Meanwhile, $23(17 \%)$ subjects reported having memory problems so acute that they felt at a disadvantage with other people. In the study 129 people (93\%) reported the fact of living as something wonderful, only 10 subjects $(7 \%)$ referred the verb live with feelings of negativity and some of them referred desires to die and episodes with suicide attempts. Regarding the difficult to start new projects and $\mathrm{n} 111$ cases $(80 \%)$ found that subjects did not refer any difficulties to carry out projects in his life while in 28 cases $(20 \%)$ said yes to have it. $72 \%$ of the cases (100 people) reported feeling still with a good level of physical energy to carry out activities while in $28 \%$ (39) this level of energy was referred as very limiting to perform activities. With respect to the desperation systems, $20 \%$ of the cases (28) reported feeling desperate at the time of obtaining data, mainly referring to health problems or problems in the family environment. However, $80 \%$ of the cases (111) reported having no reason to feel desperate. When assessing family functionality through the Family Apgar scale, it was found that $81 \%$ of the cases (112) are under a norm functional family environment, $9 \%$ (13) in a moderate dysfunctionality and rest before $10 \%(14)$ is in a severely dysfunctional family (Table 2). Analyzing the items of the scale we found that 99 people $(71 \%)$ reported maintaining the habit of discussing problems within the family context in search of agreements, 26 subjects (19\%) reported that they only talk about it on some occasions, while 14 people $(10 \%)$ almost never reported establishing family dialogue to solve problems. In $73 \%$ of the cases (101) it is mentioned that the important decisions were almost always taken together and / or taking into account the opinion of the family nucleus, in 23 cases (16\%) this habit only occurs sometimes, and in 15 cases $(11 \%)$ it was almost never used to make important decisions in the family. Regarding the satisfaction with the time spent in the family 93 cases $(67 \%)$ reported feeling almost always satisfied with the time the family devoted to coexistence, in 40 cases $(29 \%)$ only sometimes felt satisfied while in the remaining 6 cases (4\%) almost never reflected satisfaction for family coexistence. In 117 cases $(84 \%)$ older adults said they always or almost always loved by their family, while in 18 cases (13\%) they reported feeling loved only sometimes or only by some family members, finally only 4 people ( 
$3 \%$ ) almost never felt loved or valued in the family environment. After the analysis of the variables of depression and family functionality in older adults in contingency levels with Pearson Chi square tests, a value of $p=0.01$ is obtained, therefore, it is established that there is a relationship between both variables (Table 3 ).

Table 2 Results Yesave scale of older adults studied.

\begin{tabular}{ll}
\hline Variables & No. Cases \\
\hline Without symtomatology & $1 \mathrm{II}$ \\
Mild symtomatology & 20 \\
Depression & 8 \\
\hline
\end{tabular}

Source:Yasave scale $n=139$

Table 3 Family functionality of elderly patients studied

\begin{tabular}{ll}
\hline Varıables & No. Cases \\
\hline Severely dysfuntional family & 14 \\
Moderately dysfuntional family & 13 \\
Functional family & 81 \\
\hline
\end{tabular}

Source:Apgar Family n = 139 .

\section{Discussion}

After the analysis of the variables of depression and family functionality in older adults, a value of $\mathrm{p}=0.01$ is obtained. Taking into account that a value equal to or less than 0.05 in P. de Pearson reflects a correlation of variables, it is established that depression and family functionality in the elderly are related. Contrary to the results of this study, Saavedra-González et al., ${ }^{10}$ Where no established quadratic relationship between family function and depression. In this research it was found that nuclear families exert a greater degree of protection towards dysfunctionality. While in another investigation carried out in Mexico, it sustains its base of relationship between depression and functionality family. ${ }^{4}$ In this study, the results were separated for men and women and in both, a close correlation was found between the variables of depression and family functionality, resulting in $\mathrm{p}=0.01$ in both male and female gender. In their study, the findings of depression were more recurrent, in the masculine gender a prevalence of $47.2 \%$ was found and in women $51.9 \%$, while in this study the prevalence of depression established in men was only $5.7 \%$ and in women in $5.8 \%$. In both studies it has been concluded that depressive symptoms are more frequent in the female gender. ${ }^{16}$ Some authors maintain that there is a relationship between depression and family cohesion. Regarding variable Geriatric Depression converge relationship between it and the level of education $(p=0.002)$, being those with primary education who obtained major depressive score compared to those studied to higher levels. ${ }^{17}$ As in the present investigation, these authors conclude that the family functionality is related to antidepressant feelings finding a positive correlation. $(\mathrm{p}=0.001)$. They support their theory by finding a correlation now in a negative way between depression and low family cohesion. (-0.274 ns). Similarly, the findings in Torres' research ${ }^{14}$ showed a statistically significant relationship between the variables of depression and family functionality $(\mathrm{p}=0.02)$. Like this research, the percentage of functional families was higher (75\%), and also greater the absence of depressive symptoms (69\%).

They also share other demographic characteristics such as greater participation by the female gender $(61 \%)$ and primary education as the level of schooling more frequently (41\%). Contrary to these results, ${ }^{2-4}$ it is concluded that there is no association between depression and family functionality. In the cases studied, they obtained a negative correlation result of $\mathrm{p}=0.08$. They found a greater association of depressive symptomatology with factors such as age $(\mathrm{p}=0.01)$ and marital status of widowhood $(\mathrm{p}=0.007)$. In this investigation there was no inclination towards a gender in frequency to depression, affecting both in the same way. Only in $29.4 \%$ of the cases did moderate family dysfunction positive and $7.3 \%$ severe dysfunction. These authors also associated depression with age $(\mathrm{p}=0.01)$, the average age of the depressed elderly was 71.1 years and the average of adults who lacked these characteristics was 69 years, without differences by gender. In support to the results of this investigation $^{17-21}$ is a close correlation between depression and family dynamics $(\mathrm{p}=0.01)$ indicated. For this, the family environment was divided into two factors: communication and family cohesion. What confirms the accentuated in the present investigation to also consider the family as the main vital support of the human being in the stage of old age. It is also concluded in agreement with these investigations that an optimal family environment prolongs the life time and the quality.

\section{Conclusion}

At the end of the investigation it is concluded that if there is a relationship between. The variables of depression and family functionality in older adults in contingency levels with Pearson's chisquare tests obtain a value of $p=0.01$, therefore it is established that there is between both variables. Although there is a relationship of family functionality and depressive symptomatology this relationship is not always conditioning. There were isolated cases where despite family difficulties, people opted for alternatives to improve their mood as usual physical activity. In the same way, cases were found where, despite having obtained an optimal Family Apgar score; The state of depression was present since, as mentioned above, depression can be a cause of a neurotransmitter deficiency or other biological factors. Therefore, the integral assessment in the MA should include an assessment of their cognitive status and detect those conditions that generate a deterioration in their functions and their way of thinking. It is important to stop the false idea that a bad state of mind is proper to the AM, that the decline of their functions and abilities is seen normally in the aging stage.

\section{Acknowledgements}

None.

\section{Conflict of interest}

The author declares there is no conflcit of interest.

\section{References}

1. National Institute of Statistic and Geography; 2014.

2. Cuba María, Jurado Arturo, Romero Zoila, et al. Family characteristics associated with the perception of quality of life in residents of a marginal urban area in the District of Los Olivos, Lima. Rev MedHered. 2013;24 (1):12-16.

3. Castellón Castillo S, Ledesma Alonso E. Family functioning and its relationship with socialization Projections for study in a suburban community of Sancti Spiritus. Cuba, in Contributions to the Social Sciences; 2012. 
4. Mendoza-Solis L, Soler-Huerta E, Saínz-Vázquez L. Analysis of family dynamics and family functionality in primary care. Archives in Family Medicine. 2006;8(1):27-32.

5. Villarreal Amarís Gloria, Month Arrieta Edalcy. Social, welfare and functional condition of the adult over 65 in two communes of Sincelejo (Colombia). Health Barranquilla. 2012;28(1):75.

6. Hernández Z, Vázquez J, Ramo A. Depression in hospitalized older adults. A comprehensive intervention proposal to the psychologist. Electronic Journal of Medicine Health and Society. 2012;3(1):1-27.

7. Agudelo-Vélez DM, LucumiAcelas LM, Santamaría-Quiroga Y. Evaluation of depression in patients hospitalized for different medical diseases in the city of Bucaramanga. Psychological Thought. 2008;4(10):59-83.

8. World Health Organization; 2016.

9. Ruíz D, Zegbe J, Sánchez-Morales F. Depression in older adults treated in public health institutions in Zacatecas. Journal of education and development. 2014;1(1):73-78.

10. Saavedra-González A, Rángel-Torres S, García-de León A, et al Depression and family functionality in older adults of a family medicine unit in Guayalejo, Tamaulipas, Mexico. Family Care. 2016;23(1):24-28.

11. Llanes H, Lopez Y, Vázquez J, et al. Psychosocial factors that affect the depression of the elderly. Revista De Clencıas Médıcas. 2015;21(1):65-74.

12. Castellano C. The influence of social support on the emotional state and attitudes towards old age and aging in a sample of the elderly. International Journal of Psychology and Psychological Therapy. 2014;14(3):365-377.

13. Guadarrama J, Jesús Natanael, Karam Calderón, et al. Family conditions in the elderly diagnosed with depression in the Family Medicine Unit No. 222 of the IMSS; 2014.
14. Torres I. Depression and family functionality in older adults. 2012.

15. Bustos I, Sánchez J, Ulloa M. Prevalence of depression in institutionalized older adults in a geriatric home in the municipality of Chía Cundinamarca and its relationship with perception of family functionality. Savannah College. 2011

16. Escalona Pérez, B, Ruiz Martínez, AO. Mental health and family functioning in older adults of Melchor Ocampo, State of Mexico. IberoAmerican Psychology. 2016;24(1):38-46.

17. Flores-Pacheco S, Huerta-Ramírez Y, Herrera-Ramos O, et al. FAMILY AND RELIGIOUS FACTORS IN DEPRESSION IN ELDERLY ADULTS. Journal of Behavior, Health \& Social Issues. 2011;3(2):89-100.

18. White K. Emotional support of the nurse according to Peplau's Theory in the continuing ambulatory user of the Hemodialysis Unit of the Guillermo Almenara Irigoyen Hospital. URP. 2012. pp. 16-19.

19. Von Mühlenbrock F, Gómez R, Gónzalez M, et al. Prevalence of Depression in patients over 60 years of age hospitalized in the Internal Medicine Service of the Military Hospital of Santiago. Chilean journal of neuro-psychiatry. 2011;49(4):331-337.

20.Zavala-González M, Domínguez-Sosa G. Depression and perception of family functionality in Mexican urban elderly. Psychogeriatrics. 2010;2(1):41-48.

21. Quintero Á, Henao ME, Villamil MM, et al. Changes in depression and the feeling of loneliness after the therapy of laughter in elderly inpatients. Biomedical. 2015;35(1):90-100.

22. Martínez A, Pastrana E, Rodríguez-Orozco A, et al. There is a correlation between depression and family function in older adults who attend a family medicine clinic. Medical Journal of Chile. 2009;137(2):1642-1643. 